\title{
Short- and Long-Term Outcome of Balloon Dilatation of Benign Biliary
}

\section{Strictures}

\author{
Hazhir Saberi, ${ }^{1,2,}$ Somayeh Karimi, ${ }^{2}$ Bahman Rasuli, ${ }^{2}$ and Eissa Alaj ${ }^{3}$ \\ ${ }^{1}$ Advanced Diagnostic and Interventional Radiology Research Center (ADIR), Tehran University of medical Sciences, Tehran, Iran \\ ${ }^{2}$ Department of Radiology, Emam Khomeini Hospital, Tehran University of Medical Sciences, Tehran, Iran \\ ${ }^{3}$ Department of Surgery, Rasoul Akram Hospital, Iran University of Medical Sciences, Tehran, Iran \\ Corresponding author: Hazhir Saberi, Advanced Diagnostic and Interventional Radiology Research Center, Medical Imaging Center, Imam khomeini Hospital, Keshavarz \\ Blvd., Tehran, Iran. E-mail: saberi@tums.ac.ir \\ Received 2014 July 01; Revised 2015 June 30; Accepted 2015 July 11.
}

\begin{abstract}
Background: The rate of benign biliary strictures has increased in recent years.

Objectives: We studied the short- and long-term efficacy of biliary balloon dilatation in patients suffering from benign biliary strictures due to prior abdominal surgeries, such as laparoscopic cholecystectomy or liver transplantation.

Patients and Methods: An initial baseline biochemistry profile and ultrasound examination of the biliary system was done before each procedure, and 3 and 6 month follow-up sessions were completed after the completion of the biliary balloon dilatation procedure. Serum bilirubin, liver enzyme levels, and ultrasonography findings were investigated during every session.

Results: Twenty four patients, 17 females (70.8\%) and 7 males $(29.2 \%)$, were included in this study. In 21 ( $88 \%$ ) of the patients, the biliary stricture was developed after a laparoscopic cholecystectomy, while in 2 (8\%) it was a complication of a liver transplantation. The remaining patients (4\%) developed it after autoimmune pancreatitis (Whipple surgery). Among the 24 patients, 2 died within 2 months after the ballooning, mainly due to complications of their previous surgery and secondary liver cirrhosis. We found a significant decrease in serum bilirubin levels after balloon dilatation $(\mathrm{P}<0.0001)$. All the patients showed normal ultrasonography findings after the procedure, and all reported complete relief of symptoms after a 6-month period.

Conclusion: Serum bilirubin levels were significantly decreased after balloon dilatation. This procedure has led to a success rate of $95 \%$ in the short term and $91 \%$ in the long term.
\end{abstract}

Keywords: Biliary Strictures, Balloon Dilatation, Serum Bilirubin

\section{Background}

The rate of benign biliary strictures has increased in recent years, mainly due to rising numbers of laparoscopic cholecystectomies. Upper abdominal surgeries, especially cholecystectomies, are the most frequent cause (over 80\%) of benign biliary strictures. Interventional radiologic techniques such as stenting and biliary balloon dilation are the most effective techniques for managing biliary strictures in these patients (1-8).

\section{Objectives}

We studied the short- and long-term efficacy of biliary balloon dilatation in patients suffering from benign biliary strictures as a result of prior surgeries, such as laparoscopic cholecystectomy and liver transplantation.

\section{Patients and Methods}

In our before-after case series study, patients were included if they had a confirmed benign biliary stricture and showed clinical symptoms such as jaundice or pruritus, in addition to increased serum bilirubin and liver enzymes. Patients with any history of malignancy or absence of therapeutic compliance were excluded from the study. Anticoagulant agents were interrupted for 5 to 7 days, and normal coagulation profiles were documented before the procedure. After ethical clearance of the research by the ethics committee of the university, patients were provided with essential information regarding the procedure, and subsequently they all signed informed consent forms. Baseline biochemistry profiles measuring CBC-diff, bilirubin (direct and total), liver enzymes (AST, ALT, ALP), coagulation tests (PT, PTT and INR), and ultrasonography of bile ducts had been done. All procedures were done in the setting of general anesthesia. 
Initially, an ultrasound and fluoroscopic guided percutaneous transhepatic cholangiography (PTC) was carried out for each patient. Biliary duct puncture guided by ultrasound and completion of the procedure under fluoroscopy with the injection of diluted $(50 \%)$ contrast media (ultravist $300 \mathrm{mg}$ ) were accomplished. In the case of a partial stricture and the possibility of passing of the hydrophilic guide-wire and the catheter, the ballooning was performed. In the case of a complete stricture and failing to pass the guide-wire and catheter, initial external biliary drainage was achieved and a second attempt to pass was made a week later. In our study, the severity of stenosis was near total $(80 \%-100 \%)$ in all the cases (Figures 1 and 2 ).

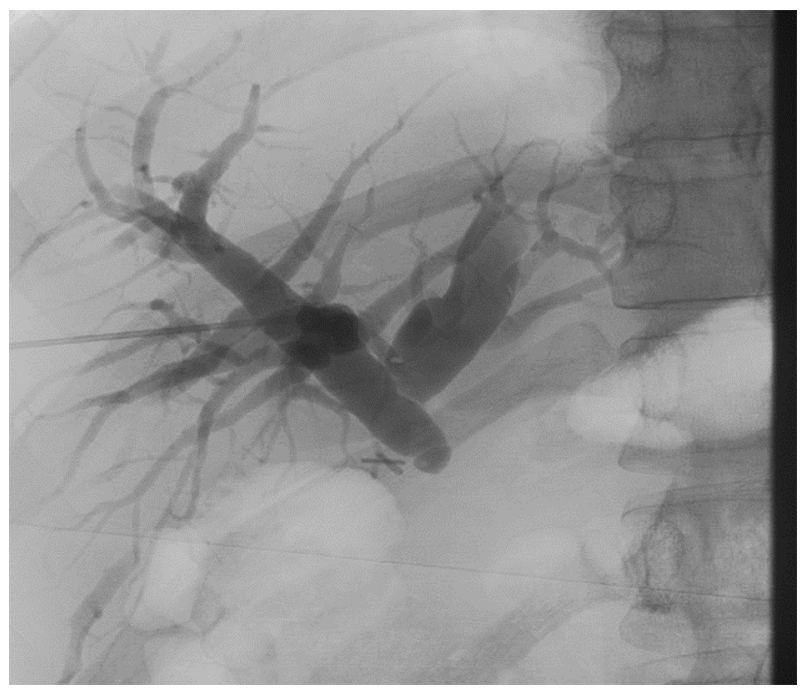

Figure 1. Percutaneous transhepatic cholangiography (PTC) after hepatojejunostomy and subsequent traumatic cholecystectomy, demonstrating complete occlusion of the anastomosis.

Once a successful ballooning was performed, an external-internal biliary drainage were carried out as well, and in case of a remaining stricture in the follow-up cholangiography (a week or two later), a second session of ballooning using a larger size was performed. It should be noted that high pressure balloons (conquest-bard) with 20 burst atmosphere pressure were employed, and the balloons were inflated with 20 atmosphere pressure and remained in place for 15 minutes.

In the first session, balloons with a diameter of up to 10 millimeters were used, and in the second session, diameters of up to 12 millimeters were used. In the case of a second-session ballooning, an external-internal catheter were left in place for two weeks in order to prevent the recurrence of strictures, cholangitis, and sepsis, and to have access for further evaluation (Figure 3 ). The length of our treatment course was variable, between 1 and 4 weeks.
All of the patients' symptoms were relieved within 1 week of a successful procedure. It should be mentioned that the resolution of symptoms was our criterion for a successful procedure, instead of the severity of residual stenosis after ballooning. Ultimately, if the procedure was considered successful, the cholangiography catheter was removed and follow-ups with an ultrasound and laboratory tests were planned for 3 and 6 months later. During the first week after the procedure, the patients were under observation for possible complications such as cholangitis, hematoma, or fibrosis, but none of these complications were observed in any of the patients.

\section{Results}

Twenty four patients, 17 females (70.8\%) and 7 males (29.2\%), were included in this study. In $21(88 \%)$ of the patients, biliary strictures developed after a laparoscopic cholecystectomy, while in $2(8 \%)$, it was a complication of a liver transplantation. In the other subject (4\%), it developed after autoimmune pancreatitis (Whipple surgery). The mean patient age was 44.83 years, with a median of 44 (age range: 25-72). Two patients died 2 months following the ballooning, due to their previous surgery complications (liver cirrhosis), and one of the patients was referred for surgical intervention due to two sessions of unsuccessful balloon dilatation.

AST levels before and after the procedure were compared using a paired t-test. The mean AST was 48.5 ( \pm 37.35 ) for the pre-procedure state and 43.09 ( \pm 37.48) for the post-procedure state; thus the patients showed no significant change in AST levels after the procedure $(\mathrm{P}=0.62)$. Likewise, ALT pre- and post-procedure levels were compared using a paired t-test. The mean ALT was 43.25, ( \pm 33.4) for the pre-procedure state and 37.77 ( \pm 30.96 ) for the post-procedure state. A paired t-test showed no significant change in ALT levels following the procedure $(\mathrm{P}=0.56)$.

We also analyzed serum bilirubin levels before and after balloon dilatation, using a paired t-test, and we found a significant decrease in serum bilirubin levels after balloon dilatation $(\mathrm{P}<0.0001)$. Regarding its technical specifications, this procedure led to a success rate of $95 \%$ (23/24) in short-term and 91\% (22/24) in long-term follow-ups. All patients showed normal ultrasonographic findings after the procedure, and all reported no biliary symptoms or complications during a six-month period following the procedure.

\section{Discussion}

The increased rate of biliary strictures in recent years is an anticipated result of the increase in the number of la- 

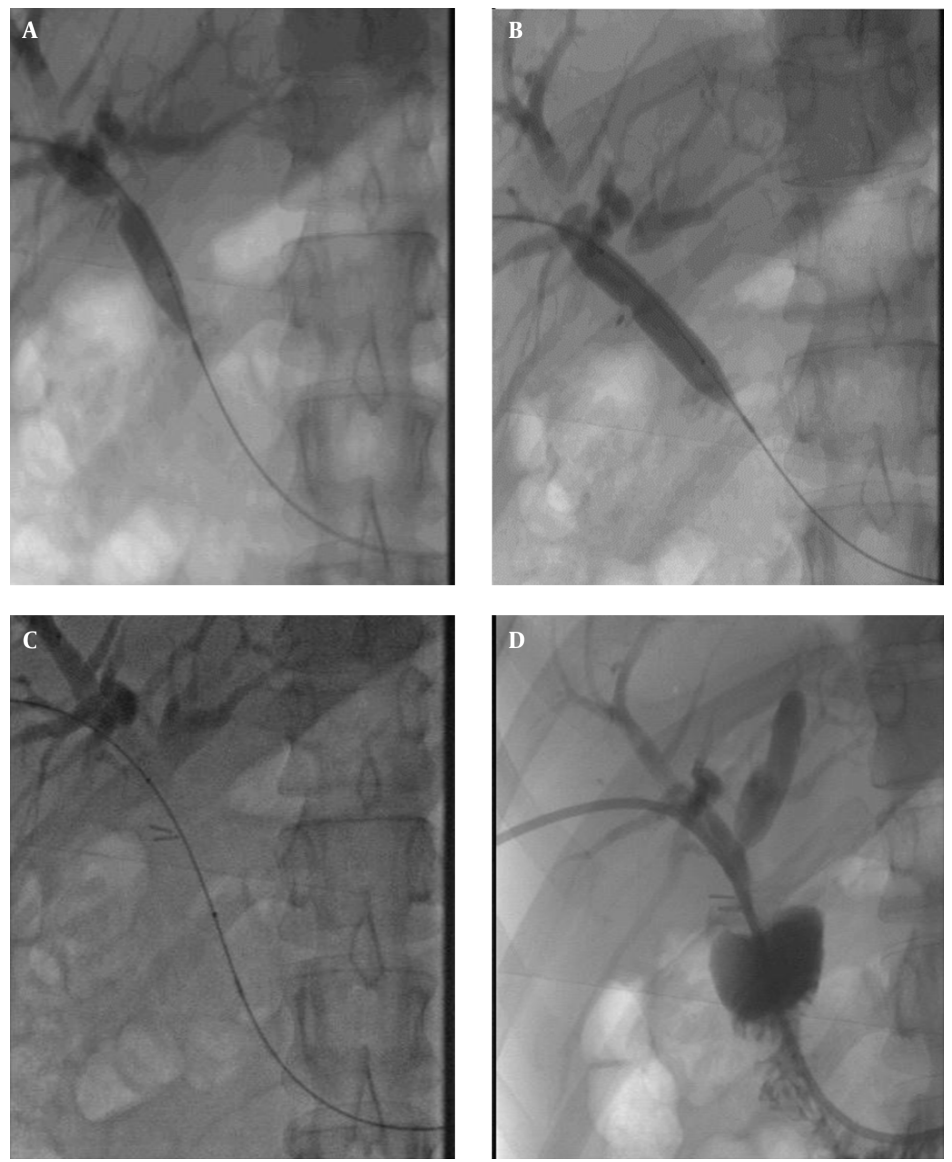

Figure 2. A-C, Images from a percutaneous transhepatic cholangiography (PTC) and ballooning dilatation of the anastomosis stricture. D, Internal-external drainage after ballooning dilatation of the anastomosis stricture

paroscopic cholecystectomy operations. Laparoscopic interventions have led to lesser hospital burden and better patient compliance, yet with increased risk of biliary damage. In initial studies, a risk of $0.1 \%$ to $0.3 \%$ was reported for this kind of complication following laparoscopic cholecystectomy, but the rate has been raised to $0.4 \%-0.6 \%$ in recent studies (1-8). On a related note, the etiology of more than $80 \%$ of biliary strictures is believed to be iatrogenic (9). This issue was also observed in our study, where $87.5 \%$ (21/24) of our patients developed biliary strictures following a laparoscopic cholecystectomy. Before the development of laparoscopic methods, the ratio of iatrogenic damage to biliary system in males was two times more than females, but this ratio has been reversed to $60 \%-80 \%$ in females after the usage of this technique (9).

Therefore, consistently with previous publications, results of our study showed this ratio to be $70 \%$ higher in females than in males.

Management of biliary strictures can be challenging, and restenosis with recurrent symptoms is commonly seen (10-13). In these patients, percutaneous trans-hepatic biliary drainage (PTBD) has been shown to be a successful method in the treatment of biliary leakage (14-16). The combination of PTBD and balloon dilation offers a less invasive approach. Several studies have shown very promising results. Technical success rates approach 93\% - 100\% with complication rates of $5 \%-20 \%$. The probability of a patient having clinically relevant restenosis at 1 year after the treatment is $0.7 \%-1.0 \%$, and it decreases to $0.56 \%-0.81 \%$ at 2 years after the treatment and $0.52 \%-0.7 \%$ at 5 years after the treatment (17-24).

Kocher et al. reported a 94\% long-term success rate in their study (22). This rate was $90 \%$ in the study of Thomas et al. (25), while Lee et al. reported a 93\% success rate (26). In our study, short term success was assessed as the absence of biliary strictures in cholangiography in the one week follow-up session, and long-term success was defined as the resolution of symptoms, normal liver func- 

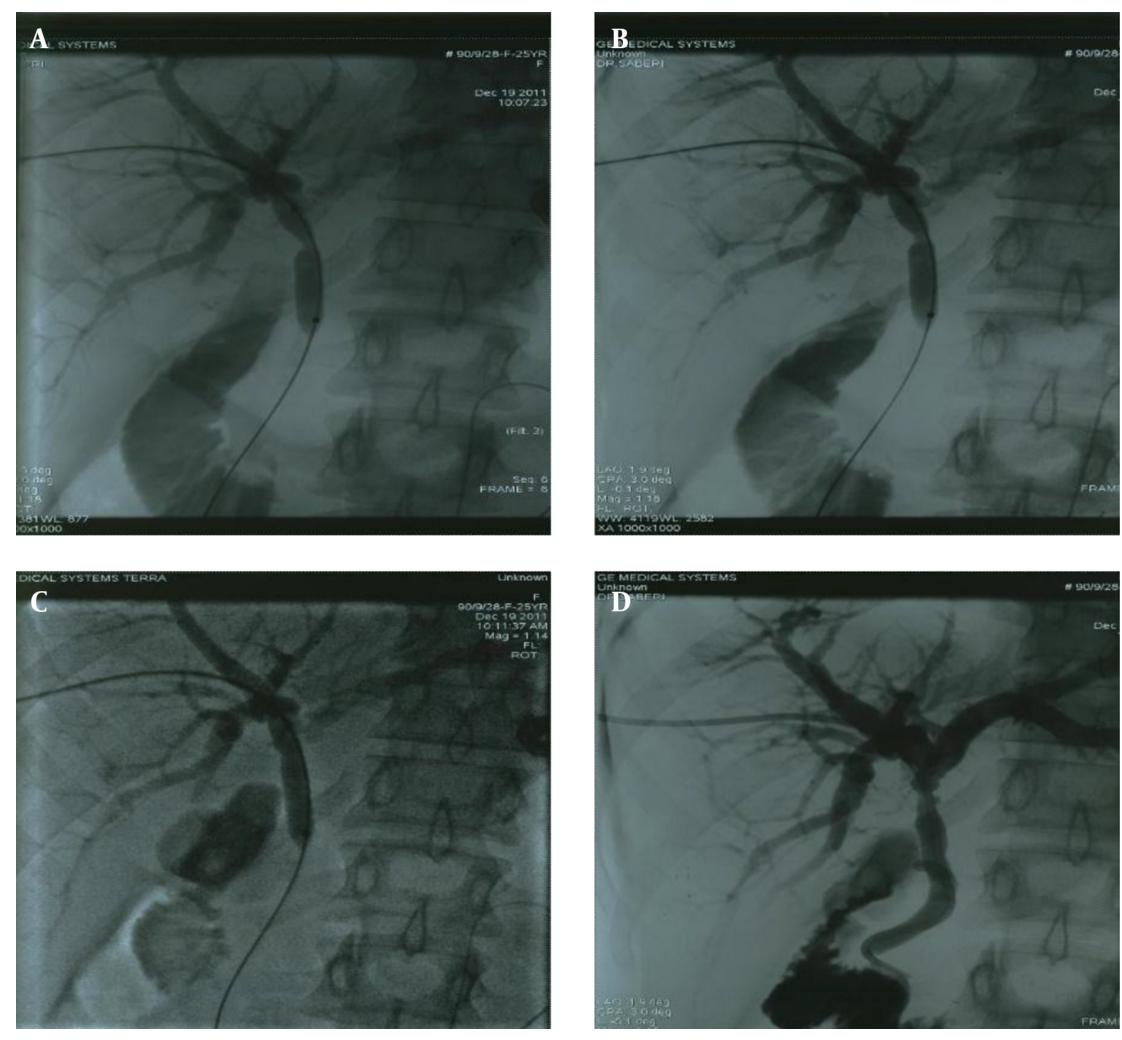

Figure 3. A-D, An endoscopic retrograde cholangio-pancreatography (ERCP) image showing complete occlusion of the common bile duct in a 25 year old woman after a laparoscopic cholecystectomy. The percutaneous transhepatic cholangiography (PTC) view shows that the balloon is advanced over a guide wire and is inflated across the common bile duct. A widely opened stricture is observed after balloon dilation.

tion tests, and a normal ultrasound examination in 3- and 6-month follow-up sessions. Except for one patient which needed a re-insertion of the balloon dilatator, in this study, all cases were considered successful, as evaluated by the post-procedure cholangiography (95\% short-term success rate). In terms of the long-term success rate, 2 patients died about 2 months after the procedure (due to complications of previous surgery). Despite a non-significant decrease in their liver enzyme levels, we cannot use the significant decrease in serum bilirubin level and the absence of clinical symptoms and normal sonography reports after 6 months to define these two cases as successful procedures, which leads to a $91 \%$ long-term success rate for our study. Sepsis, cholangitis, hemorrhage, and biliary fistulas to adjacent organs are the most common complications following ballooning of biliary strictures (1-8). In our study, the biliary ballooning was successful in all patients, with no serious complications.

According to our findings, laparoscopic cholecystectomy was the most frequent cause of benign biliary strictures (87.5\%). In accordance with previous studies, most
(70\%) of the patients with benign biliary strictures were female. This fact may be due to more frequent procedures on females because gallbladder stones are more prevalent in this gender, resulting in an increased rate of laparoscopic surgeries. There was no significant correlation between the time after the surgery which caused the biliary stricture and the increase in serum bilirubin levels in patients after biliary balloon dilatation $(\mathrm{P}=0.34)$. Serum levels of AST and ALT in patients following biliary balloon dilatation were not significantly decreased because they were not high before the procedure $(\mathrm{P}>0.5)$. However, serum bilirubin level significantly decreased after balloon dilatation $(\mathrm{P}<0.0001)$.

\section{Acknowledgments}

The authors hereby acknowledge the staff of the radiology center of Imam Khomeini hospital, Tehran, for their kindness. 


\section{Footnotes}

Authors' Contribution: Hazhir Saberi observed the design and data collection and the procedures for each case; Somayeh Karimi prepared the draft of the manuscript and contributed to data collection, Bahman Rasuli contributed to data collection, and Eissa Alaj was in charge of statistics and manuscript revisions.

Financial Disclosure: None declared.

Funding/Support: This study was done under financial support from Tehran University of Medical Sciences.

\section{References}

1. McMahon AJ, Fischbacher CM, Frame SH, MacLeod MCM. Impact of laparoscopic cholecystectomy: a population-based study. The Lancet. 2000;356(9242):1632-7. doi:10.1016/S0140-6736(00)03156-1.

2. Svab J, Peskova M, Krska Z, Gurlich R, Kasalicky M. Prevention, diagnosis and treatment of iatrogennic lesions of biliary tract during laparoscopic cholecystectomy. Management of papila injury after invasive endoscopy. Part 1. Prevention and diagnosis of bile duct injuries. Rozhledy v chirurgii: mesicnik Ceskoslovenske chirurgicke spolecnosti. 2005;84(4):176-81. [PubMed: 15984144].

3. Deziel DJ, Millikan KW, Economou SG, Doolas A, Ko S, Airan MC. Complications of laparoscopic cholecystectomy: a national survey of 4,292 hospitals and an analysis of 77,604 cases. Am JSurg.1993;165(1):914. doi:10.1016/S0002-9610(05)80397-6. [PubMed: 8418705].

4. Sicklick JK, Camp MS, Lillemoe KD, Melton GB, Yeo C, Campbell KA, et al. Surgical management of bile duct injuries sustained during laparoscopic cholecystectomy: perioperative results in 200 patients. Ann Surg. 2005;241(5):786-95. [PubMed: 15849514].

5. Misra M, Schiff J, Rendon G, Rothschild J, Schwaitzberg S. Laparoscopic cholecystectomy after the learning curve: what should we expect?. Surg Endosc. 2005;19(9):1266-71. doi: 10.1007/s00464-004-89195. [PubMed: 16021365].

6. Archer SB, Brown DW, Smith CD, Branum GD, Hunter JG. Bile duct injury during laparoscopic cholecystectomy: results of a national survey. Ann Surg. 2001;234(4):549-59.

7. Jones DB, Soper NJ. Complications of laparoscopic cholecystectomy. J Natl Med Assoc. 1996;47(1):31-44. doi: 10.1146/annurev.med.47.1.31. [PubMed: 8712784].

8. Kunasani R, Kohli H. Significance of the cystic node in preventing major bile duct injuries during laparoscopic cholecystectomy: a technical marker. J Laparoendosc Adv Surg Tech. 2003;13(5):321-3. doi: 10.1089/109264203769681718. [PubMed: 14617391].

9. Gronroos JM, Karvonen J, Hurme S, Salminen P. Stone or stricture: does the calibre of intrahepatic bile ducts predict the diagnosis?.ANZ J Surg. 2012;82(1-2):89. doi: 10.1111/j.1445-2197.2011.05933.x. [PubMed: 22507510].

10. Ahrendt SA, Pitt HA. Surgical therapy of iatrogenic lesions of biliary tract. World J Surg. 2001;25(10):1360-5. [PubMed: 11596904].

11. Lillemoe KD, Melton GB, Cameron JL, Pitt HA, Campbell KA, Talamini MA, et al. Postoperative bile duct strictures: management and outcome in the 1990s. Ann Surg. 2000;232(3):430-41.
12. Pitt HA, Kaufman SL, Coleman J, White RI, Cameron JL. Benign postoperative biliary strictures. Operate or dilate?.Ann Surg. 1989;210(4):417.

13. Sheridan JS, Maclennan AC. Percutaneous transhepatic use of a cutting balloon in the treatment of a benign common bile duct stricture. Cardiovasc Interv Radiol. 2007;30(2):346.

14. Cozzi G, Severini A, Civelli E, Milella M, Pulvirenti A, Salvetti M, et al. Percutaneous transhepatic biliary drainage in the management of postsurgical biliary leaks in patients with nondilated intrahepatic bile ducts. Cardiovasc Intervent Radiol. 2006;29(3):380-8. doi: 10.1007/s00270-005-0102-4. [PubMed: 16502179].

15. Kim J, Ko G, Sung K, Yoon H, Gwon D, Kim K, et al. Bile leak following living donor liver transplantation: clinical efficacy of percutaneous transhepatic treatment. Liver Transplantation. 2008;14(8):1142-9. doi: 10.1002/lt.21501. [PubMed: 18668647].

16. Baker TA, Aaron JM, Borge M, Pierce K, Shoup M, Aranha GV. Role of interventional radiology in the management of complications after pancreaticoduodenectomy. Am J Surg. 2008;195(3):386-90. doi: 10.1016/j.amjsurg.2007.12.026. [PubMed: 18308043].

17. Cantwell CP, Pena CS, Gervais DA, Hahn PF, Dawson SL, Mueller PR. Thirty years' experience with balloon dilation of benign postoperative biliary strictures: Long-term outcomes 1. Radiology. 2008;249(3):1050-7. doi: 10.1148/radiol.2491080050. [PubMed: 18812559].

18. Lubienski A, Duex M, Lubienski K, Blietz J, Kauffmann GW, Helmberger $\mathrm{T}$. Interventionen bei benignen Gallengangstenosen. Der Radiologe. 2005;45(11):1012-9. doi: 10.1007/s00117-005-1299-6.

19. Bonnel DH, Fingerhut AL. Percutaneous transhepatic balloon dilatation of benign bilioenteric strictures: long-term results in 110 patients. Am J Surg. 2012;203(6):675-83. doi: 10.1016/j.amjsurg.2012.02.001.

20. Kucukay F, Okten RS, Yurdakul M, Ozdemir E, Erat S, Parlak E, et al. Long-term results of percutaneous biliary balloon dilation treatment for benign hepaticojejunostomy strictures: are repeated balloon dilations necessary?.J Vasc Interv Radiol. 2012;23(10):1347-55. doi: 10.1016/j.jvir.2012.07.004.

21. Ko G, Sung K, Yoon H, Kim K, Gwon D, Lee S. Percutaneous transhepatic treatment of hepaticojejunal anastomotic biliary strictures after living donor liver transplantation. Liver Transplant. 2008;14(9):1323-32. doi: 10.1002/lt.21507.

22. Kocher M, Cerna M, Havlík R, Kral V, Gryga A, Duda M. Percutaneous treatment of benign bile duct strictures. European journal of radiology. 2007;62(2):170-4. doi:10.1016/j.ejrad.2007.01.032.

23. Vos PM, Van Beek EJR, Smits NJ, Rauws EAJ, Gouma DJ, Reeders JWAJ. Percutaneous balloon dilatation for benign hepaticojejunostomy strictures. Abdom Imaging. 2000;25(2):134-8. doi: $10.1007 /$ s002619910032.

24. Zajko AB, Sheng R, Zetti GM, Madariaga JR, Bron KM. Transhepatic balloon dilation of biliary strictures in liver transplant patients: a 10-year experience. J Vasc Interv Radiol. 1995;6(1):79-83. [PubMed: 7703586].

25. Thomas R, Köcher M, Cerna M, Kozak J, Burval S, Havlik R. Is the biliary manometric perfusion test effective in the evaluation of balloon dilatation treatment success of benign biliary strictures?. Biomed Papers. 2009;153(2):153-6. doi: 10.2214/ajr.157.6.1950878. [PubMed: 1950878].

26. Lee MJ, Mueller PR, Saini S, Hahn PF, Dawson SL. Percutaneous dilatation of benign biliary strictures: single-session therapy with general anesthesia. AJR. American journal of roentgenology.1991;157(6):1263-6. 